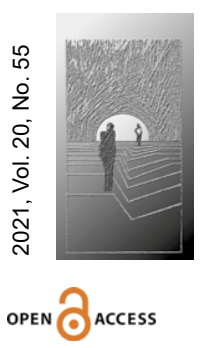

Patrycja Mizera-Pęczek

https://orcid.org/0000-0001-9637-3263 Uniwersytet Łódzki patrycja.mizera@uni.lodz.pl

Anna Krasnova

https://orcid.org/0000-0003-2832-2100

Uniwersytet Łódzki

anna.krasnova@uni.lodz.pl

DOI: 10.35765/hw.2046

\title{
Codzienność zawodowa instamatek w okresie pandemii
}

\section{STRESZCZENIE:}

CEL NAUKOWY: Celem naukowym niniejszego artykułu jest przedstawienie opisów codzienności zawodowej instamatek w kontekście przemian, które narzuciła rodzinom sytuacja epidemiczna w Polsce.

PROBLEM I METODY BADAWCZE: Problemem badawczym rozpatrywanym w niniejszym artykule jest konieczność reorganizacji życia codziennego instamatek w okresie pandemii. Przeprowadzone badanie miało charakter jakościowy, interpretatywny i zostało zrealizowane za pomocą metody analizy treści publikowanych przez instamatki.

PROCES WYWODU: W pierwszej części dokonano przeglądu literatury dotyczącej roli mediów społecznościowych w życiu codziennym kobiet, w tym tych, które posiadają dzieci, oraz przemian sytuacji zawodowej matek w 2020 roku. W drugiej części artykułu zaprezentowano rezultaty badań własnych zrealizowanych metodą analizy treści postów udostępnianych przez matki na Instagramie w okresie pandemii.

WYNIKI ANALIZY NAUKOWEJ: Rezultatem badań własnych jest gęsty opis codzienności matek w okresie pandemii w perspektywie kobiet, które dzielą się swoimi doświadczeniami na Instagramie.

WNIOSKI, INNOWACJE, REKOMENDACJE: Dotychczasowe rekomendacje praktyk służących kształtowaniu równowagi praca - życie stały się nieadekwatne do pandemicznej codzienności pracujących matek.

$\rightarrow$ SŁOWA KLUCZOWE: CODZIENNOŚĆ ZAWODOWA, MACIERZYŃSTWO, INSTAMATKA, MEDIA SPOKECZNOŚCIOWE, PANDEMIA, INSTAGRAM 


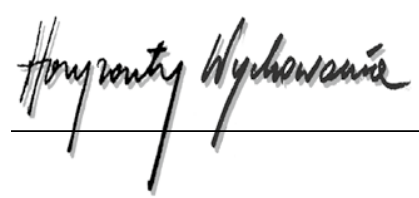

ABSTRACT

Daily Professional Life of Instamums During the Pandemic

RESEARCH OBJECTIVE: The scientific aim of this article is to present the daily life of female insta-women in the context of changes that have been imposed on families by the epidemic situation in Poland.

THE RESEARCH PROBLEM AND METHODS: The research problem discussed in this article is the need to reorganize the everyday life of instamums women during a pandemic.

THE PROCESS OF ARGUMENTATION: The first part reviews the literature on the role of social media in daily life of women, including those who have children, and the transformations in the professional situation of mothers in 2020 . The second part of the article presents the results of own research carried out by the method of analysis the content of posts shared by mothers on Instagram during the pandemic.

RESEARCH RESULTS: The result of our own research is a thick description of daily life of mothers during the pandemic from the perspective of women who share their experiences with Instagram.

CONCLUSIONS, INNOVATIONS, AND RECOMMENDATIONS: The current recommendations for practices aimed at shaping the work-life balance have become inadequate to the pandemic daily life of working mothers.

\section{$\rightarrow$ KEYWORDS: DAILY LIFE, DAILY WORK, INSTAMUMS, SOCIAL MEDIA, PANDEMIC, INSTAGRAM}

\section{Wstęp}

Media społecznościowe na stałe wpisały się we współczesną rzeczywistość. Według danych pochodzących z raportu Statshot już ponad 4,1 miliarda ludzi na całym świecie posiada konto choć na jednym portalu społecznościowym. W 2020 roku na aktywność w mediach społecznościowych użytkownicy przeznaczali blisko 2,5 godziny dziennie, co stanowiło prawie 1/3 czasu spędzonego online. Bez wątpienia swój wpływ miała na to również pandemia koronawirusa COVID-19. Blisko połowa populacji Polski posiada aktywne konta w mediach społecznościowych i tylko w ostatnim roku w Polsce przybyło aż 1,4 miliona nowych użytkowników (Kemp, 2020). Na podstawie analizy literatury dotyczącej korzystania z mediów społecznościowych (Uzależnienia behawioralne, b.d.; Kowalska, 2016, s. 373) stwierdzono, że to właśnie kobiety stanowią największą grupę użytkowników tzw. mediów lifestylowych, takich jak Pinterest, Facebook czy Instagram. Co ciekawe, w ostatnich latach kobiety zdecydowanie wolą korzystać z Instagrama niż np. Facebooka (CBOS, 2019, s. 70). W literaturze podkreślane są dwa motywy obecności użytkowników w tym medium. Po pierwsze jest to kreowanie profilu przez osoby 
rozpoznawalne w celu podejmowania współpracy z markami w ramach marketingu internetowego oraz kreowanie profili przez osoby, które aspirują do bycia wpływowymi i podejmują działania, które mają prowadzić do wzrostu ich popularności (Boerman, 2020, s. 199). Obecnie Instagram zajmuje 4. miejsce według popularności wśród polskich użytkowników mediów społecznościowych, korzysta z niego 7,3 miliona osób (Kemp, 2020).

Ponadto w mediach społecznościowych zauważalny jest wzrost aktywności matek (CBOS, 2019, s. 73) oraz profesjonalizacja ich internetowych profili (Moujaes i Verrier, 2020, s. 4). Często publikacje autorstwa matek dotyczą problematyki rodziny widzianej z dwóch perspektyw: zewnętrznej kreacji i wewnętrznej rzeczywistości, która dotyczyć może rutyny dnia codziennego (Łosiewicz, 2020, s. 137). Większość publikacji (tzw. postów) w mediach społecznościowych opatrzonych jest słowami kluczowymi (hasztagami), które służą grupowaniu i odnajdywaniu treści o podobnym znaczeniu (IAB Polska, b.d.). Jednym z takich słów kluczowych jest hasztag \#instamatka odnoszący się do aktywnych na Instagramie kobiet posiadających dzieci. Wśród instamatek można dostrzec również instamatki influencerki, czyli takie kobiety, które udostępniają osobliwości swojego macierzyństwa po to między innymi, by mieć wpływ na inne matki, kreować się jako specjalistki, wyznaczać trendy i zrzeszać znaczną grupę obserwatorów (Urbaś, 2021, s. 81). Instamatki influencerki pokazują swoje macierzyństwo w sposób ciekawy i niezwykły, inspirując tym samym inne kobiety do podobnej aktywności w mediach społecznościowych (Buksa i Luber, 2020, s. 60).

Warto podkreślić, że zwłaszcza młode matki, które mogą doświadczać poczucia utraty kontroli nad własnym życiem i samotności - wynikających z izolacji rodziny nuklearnej ze środowiska społecznego (Grotowska, 2019, s. 32) - decydują się na sięganie po urządzenia mobilne w celach terapeutycznych. Aktywność w mediach społecznościowych jest dla nich substytutem relacji towarzyskich, ale i sposobem spędzania czasu, który może być przez nie postrzegany jako bezproduktywny (np. podczas drzemki dziecka) (Bednarska, 2020, s. 9-10; CBOS, 2019, s. 73-74). Ponadto aktywność matek w mediach społecznościowych jest rodzajem samoujawniania i społecznego dzielenia się emocjami, czego walorem jest reakcja zwrotna innych użytkowników, np. w postaci tzw. lajków, komentarzy czy dzielenia się postem poprzez jego udostępnianie (Pluta, 2020, s. 40; Belanche i in., 2020, s. 47). I choć do niedawna aktywność w Instagramie była traktowana przez kobiety ,jako rozrywkowy przerywnik i wypełniacz czasu pomiędzy różnymi aktywnościami domowymi i zawodowymi” (CBOS, 2019, s. 75), obecnie stanowi narzędzie do szczerego dzielenia się codzienną rzeczywistością.

Mnogość profili instamatek skłania kobiety do chęci wyróżnienia się i pokazania swojego macierzyństwa w kontekście łączenia ról rodzicielskich z zawodowymi, stąd wzrost popularności postów oznaczonych hasztagami: \#matkapracująca, \#pracującamama czy \#mamawracadopracy (Krasnova i Mizera-Pęczek, w druku). Stało się to przesłanką do zainteresowania się autorek artykułu tematyką poruszaną przez matki aktywne zawodowo w postach publikowanych w mediach społecznościowych. Celem niniejszego artykułu jest zatem przedstawienie opisów codzienności zawodowej instamatek w okresie pandemii. 


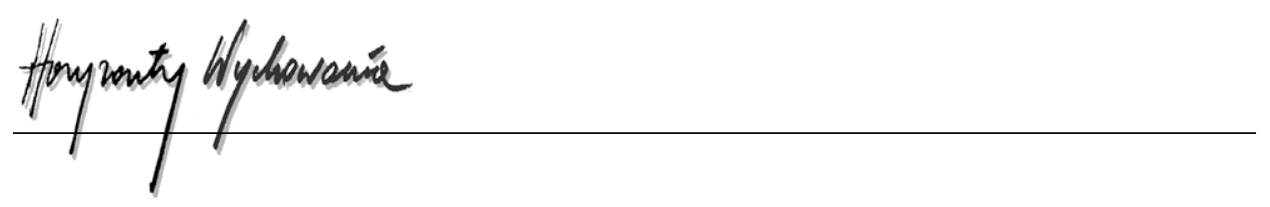

\section{Sytuacja zawodowa instamatek w okresie pandemii}

Aktywność zawodowa kobiet jest istotnym czynnikiem społeczno-gospodarczego rozwoju kraju. Należy jednak dostrzec, że sytuacja kobiet na rynku pracy jest (w porównaniu z mężczyznami) gorsza, na co wskazuje wyższy poziom bezrobocia oraz niższy poziom wynagrodzenia za pracę. Nierówności te pogłębiły się w okresie pandemii (Młyński, 2020, s. 76; Zub, 2020, s. 34; Eurofound, 2020, s. 24), kiedy matki w znakomitej większości przejęły obowiązki rodzicielskie i były zobligowane do łączenia ich z obowiązkami zawodowymi w warunkach nowej codzienności (Eurofound, 2020, s. 2, 4; Deloitte, 2021, s. 3).

Według badania przeprowadzonego w 27 państwach UE to właśnie kobiety są bardziej niż mężczyźni narażone na utratę pracy w związku z pandemią COVID-19 (Eurofound, 2020, s. 9-10). Co więcej, kobiety w okresie pandemii częściej niż mężczyźni pracowały na podstawie umów na czas określony oraz w mniejszym wymiarze czasu pracy (Eurofound, 2020, s. 10-11). Ponadto kobiety częściej deklarowały, że ich gospodarstwo domowe ma trudności finansowe w zakresie niezbędnych wydatków (Eurofound, 2020, s. 17). Badania przeprowadzone zarówno na początku pandemii (w kwietniu 2020 r.), jak i w połowie 2020 roku wykazały, że zwłaszcza kobiety z dziećmi do 12. roku życia miały szczególne problemy w zakresie utrzymania równowagi pomiędzy życiem zawodowym a prywatnym. Powodem tego była chociażby konieczność przejścia na pracę zdalną (Eurofound, 2020, s. 21; Deloitte, 2021, s. 3). Trudności w tym zakresie sprawiała również edukacja zdalna starszych dzieci lub brak możliwości zapewnienia opieki młodszym dzieciom w związku z czasowym zamknięciem takich placówek edukacyjnych, jak żłobki czy przedszkola (Deloitte 2021, s. 5). Warto zwrócić uwagę, że kobiety w trakcie pandemii także gorzej niż mężczyźni radziły sobie psychicznie (Deloitte 2021, s. 3) i miały mniej pozytywne nastawienie do sytuacji związanej z życiem społecznym i gospodarczym (Eurofound, 2020, s. 25, 27).

W badaniu przeprowadzonym przez firmę Deloitte wśród blisko 400 pracujących kobiet z dziewięciu państw oraz 335 pracujących kobiet z Polski wykazano, że 7 na 10 kobiet uważa, iż pandemia stanowi poważne zagrożenie dla ich kariery zawodowej (Deloitte, 2021, s. 2-3).

Z danych Raportu „Mama-Warszawianka” (Raport, b.d., s. 4-5) wynika, że aż 1/4 ankietowanych mieszkanek stolicy w czasie pandemii straciła pracę zarobkową, zaś $28 \%$ zarabia mniej niż przed pandemią. Badanie przeprowadzono w październiku 2020 roku na próbie 524 kobiet aktywnych zawodowo mieszkających w Warszawie. Ponad 70\% z nich uważa, że przez pandemię ma mniejsze możliwości zawodowe (Raport, b.d., s. 11), natomiast aż 53\% twierdzi, że ma utrudniony rozwój zawodowy przez fakt bycia matką (Raport, b.d., s. 12). Z raportu wynika również, że pandemia spowodowała, iż $30 \%$ badanych kobiet pracuje więcej (o co najmniej pół godziny dziennie), z kolei 34\% ma więcej obowiązków zawodowych (Raport, b.d., s. 6-7). 


\section{Metodyka badań własnych}

W związku z opisanymi we wcześniejszych częściach artykułu przesłankami autorki artykułu podjęły próbę analizy jakościowej dyskursu wybranych postów opublikowanych na Instagramie. Celem badania było rozpoznanie doświadczeń związanych z łączeniem ról rodzicielskich i zawodowych przez aktywne zawodowo instamatki w okresie pandemii. Choć najważniejszym narzędziem komunikacji na Instagramie jest umieszczanie w tym medium fotografii, to właśnie słowna część publikacji stanowiła dla autorek najważniejsze źródło eksploracji badanej tematyki.

Obszar eksploracji stanowiły posty publikowane w medium społecznościowym Instagram przez kobiety pracujące i posiadające dzieci. Badanie przeprowadzono w marcu 2021 roku. Objęło ono posty opublikowane w ciągu roku trwania pandemii w Polsce (przyjęto, że jest to okres od 1 marca 2020 do 28 lutego 2021 roku). Dobór postów do analizy miał charakter celowy. Kryterium doboru było zastosowanie przez autorkę postu jednego z następujących hasztagów: \#mamapracująca (1640 postów), \#mamapracujaca (3153 postów), \#matkapracująca (3143 postów), \#matkapracujaca (1216 postów). Selekcja postów do analizy miała charakter jakościowy. Przy tworzeniu bazy danych autorki odrzucały wszystkie posty, które zostały opatrzone video lub dowolnego rodzaju grafiką zamiast zdjęcia, które stanowi najważniejsze narzędzie komunikacji na Instagramie. Ponadto odrzucono posty opublikowane przez innych autorów niż instamatki (mężczyźni oraz instytucje). Do badania wyselekcjonowano 312 postów. Analizując wyselekcjonowane posty, autorki poszukiwały odpowiedzi na następujące pytania badawcze:

1. Czego dotyczą publikacje aktywnych zawodowo instamatek w okresie pandemii?

2. Na jakie aspekty łączenia pracy i macierzyństwa zwracają uwagę instamatki?

3. Jakich trudności wynikających z funkcjonowania w pandemicznej rzeczywistości doświadczają pracujące instamatki?

4. Jakie atuty nowej pandemicznej rzeczywistości zauważają instamatki?

Aby udzielić odpowiedzi na tak postawione pytania badawcze, autorki przyjęły jakościową orientację metodologiczną, a rezultaty badań przedstawiły w formie gęstego opisu (Geertz, 2003, s. 35). Publikację wzbogacono fragmentami postów. W nawiasach przedstawiono numer porządkowy badanego postu, z którego pochodzi cytat.

\section{Rezultaty badań}

Analizowane przez autorki posty dotyczyły różnorodnych aspektów łączenia ról macierzyńskich z pracą zawodową w nowej codzienności naznaczonej pandemią. Zgodnie z założeniami badawczymi matki aktywne w medium społecznościowym Instagram dzieliły się w przestrzeni wirtualnej swoimi doświadczeniami radzenia sobie z nowymi dla nich sytuacjami i rewidowaniem dotychczasowych praktyk codzienności.

Warto zwrócić uwagę, że analizowane publikacje dostarczyły autorkom możliwość przypuszczenia, że mamy aktywne zawodowo w okresie pandemii szczególnie potrzebują 


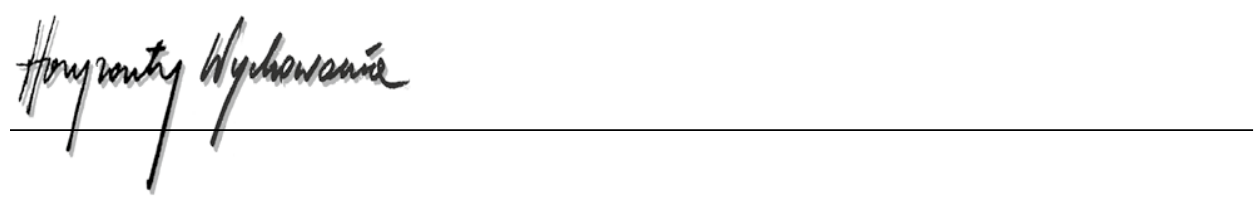

dzielić się z innymi osobami pozytywnymi aspektami swojej codzienności. Staje się to widoczne m.in. w postach dotyczących celebrowania różnych świąt rodzinnych (209, 230) czy codziennych przyjemności, takich jak np. otrzymanie niespodziewanego prezentu (202).

Nadanie badanym postom kategorii analitycznych pozwoliło wyselekcjonować najważniejsze, z punktu widzenia niniejszego opracowania, publikacje (kategoria „praca zawodowa” oraz „sprzedaż bezpośrednia”). Niektóre matki aktywne na Instagramie wykorzystują to medium społecznościowe do prowadzenia działalności zawodowej („sprzedaż bezpośrednia"). Matki, których posty zakwalifikowano do opisywanej kategorii, wykonują pracę w różnych zawodach. Są to np. kosmetyczki (269), specjalistki ds. handlu $(1,21,256,267)$, producentki odzieży $(217)$, pisarki $(251)$, trenerki $(5,36,51)$, fotografki (248), marketerki (194), a nawet psycholożki (65) czy przedsiębiorczynie $(239,281)$.

Co ciekawe, blisko 1/3 postów z kategorii „sprzedaż bezpośrednia” poświęcono szeroko pojętej tematyce prowadzenia działalności gospodarczej przez kobiety. W swoich publikacjach instamatki zachęcały inne kobiety do założenia własnej firmy i rozwinięcia swoich pomysłów biznesowych czy też dołączenia do budowania już działających przedsięwzięć:

\footnotetext{
Emocje jeszcze nie opadły. Powiem szczerze, że ja chyba jeszcze do końca nie wierzę, że to się stało! Minął nieco ponad rok, od kiedy podjęłam bardzo spontaniczną decyzję o rozpoczęciu biznesu e-commerce, a dziś mogę cieszyć się z tytułu udziałowca. Rok temu byłam pełna obaw, nie miałam doświadczenia w żadnym biznesie, nie wiedziałam jak „ugryźć" działalność w social media (239).
}

Ponadto w publikowanych postach kobiety dzieliły się swoimi doświadczeniami i opowiadały o tym, co sprawiło, że zdecydowały się na założenie własnego biznesu (281).

Warto wspomnieć, że komunikacja prowadzona przez instamatki w postach, które zakwalifikowały się do opisywanej kategorii, bardzo często miała charakter motywacyjny. Matki pracujące, odnosząc się do wykonywanej przez nie pracy i swoich doświadczeń, zachęcały inne kobiety do podnoszenia swoich kwalifikacji i rozwoju zainteresowań:

Bardzo zależało mi na jej [książki] powstaniu, abym mogła zamknąć superważny etap w moim życiu, przekazać w niej wszystko, czego się nauczyłam i abym mogła pójść dalej (251).

Analizując materiał badawczy, autorki odniosły wrażenie, że dzieląc się swoimi spostrzeżeniami i realiami prowadzenia działalności zawodowej, instamamy próbowały dodać otuchy innym kobietom, przekazać, że każda, która decyduje się na łączenie roli matki z rolą aktywnej zawodowo kobiety, ma trudności, ale też każda może sobie z nimi poradzić.

P.S. Wprawne oko zobaczy w tle drewniane tory kolejowe, do układania których moje dziecko jest przekonane, że istnieje biuro rodziców oraz jakąś niezidentyfikowaną mieszankę 
koców oraz kołder, które są jej wizją domku dla lali oraz wagoników pociągu. I właśnie takie widoki też są elementem mojego biznesu, a ja mam wielkie przekonanie, że jest to bardzo ok (251).

Na uwagę zasługuje fakt, że niemal wszystkie autorki postów, które zakwalifikowano do opisywanej kategorii, pozycjonowały siebie jako kobiety silne, zdeterminowane i pełne pomysłów.

(...) wierzymy $w$ to, że jest tu więcej kobiet takich jak my, łączących wiele ról w jednym życiu. Odważnych, nieustraszonych, ambitnych i wierzących w to, że są wystarczająco dobre. Wiemy, że tu pasujesz i jest to miejsce dla Ciebie (45).

Do kolejnej analizowanej kategorii autorki przypisały posty, które dotyczyły pracy zawodowej instamatek. Komunikaty matek zawierały opisy codziennych doświadczeń funkcjonowania pracujących mam, dla których Instagram nie jest narzędziem pracy (jak w przypadku kategorii „sprzedaż bezpośrednia”), lecz współczesnym pamiętnikiem.

Instamamy przypisały znaczenie reorganizacji ich codzienności w czasie pandemii. Ważną dla instamatek zmianą była konieczność pracy w trybie home office w czasie, gdy inni domownicy zajmowali domową przestrzeń swoimi codziennymi aktywnościami. O ile w literaturze z obszaru zarządzania zasobami ludzkimi publikowanej w okresie przed pandemią możliwość pracy zdalnej oraz inne praktyki służące wzmacnianiu elastyczności były pożądanymi przez matki benefitami, o tyle w sytuacji pandemii, gdy matki przejęły obowiązki nauczycieli, opiekunów dzieci oraz obowiązki domowe, wykonywanie przez nie pracy zawodowej było niezwykle utrudnione. Instamatki dzieliły się w mediach społecznościowych informacjami o sposobie wykonywania przez nie pracy z domu, zwracając uwagę na chałupniczy sposób organizowania swojej przestrzeni do pracy i nieustanny pośpiech, który towarzyszył ich codzienności.

Tak wyglądałby idealny home office. Tymczasem siedzę na łóżku dziecka, przy niskim stoliku, lekko zgarbiona, z drugim monitorem ustawionym na stosie książek i kilkoma kablami dookoła (272).

Wieczorny spacering przed nocnym posiedzeniem przed kompem... Mam wrażenie, że wiecznie jestem w niedoczasie, wiecznie mam coś na głowie, wiecznie wiszę komuś sesję, wiecznie biegnę na jakąś i wiecznie szukam opieki dla dzieci, żeby na tę sesję się wyrwać (291).

Kiedy wszyscy już dawno uspani, a ja w ciszy i spokoju mogę pracować nad nowym projektem (305).

Home office w wolnym tłumaczeniu: pracujesz w każdej wolnej chwili i miejscu, gdzie nie ma dzieci (313).

Pracujące Instamamy dzieliły się w swoich wpisach emocjami związanymi z nowymi wyzwaniami macierzyństwa. Kobiety aktywne w social mediach coraz śmielej przełamują 




utrwalony wizerunek nieustraszonej matki Polki, która radzi sobie z każdym zadaniem wymagającym łączenia pełnionych przez nią funkcji zawodowych i rodzicielskich. W narracjach instamam można rozpoznać opisy całego wachlarza uczuć towarzyszących im w okresach zaostrzania i luzowania obostrzeń: od zawiedzenia rozwiązaniami w zakresie zdalnej edukacji dzieci, działania placówek opiekuńczych, nowego funkcjonowania miejsc pracy, po poczucie zagubienia czy braku akceptacji nowego porządku codzienności. Matki komunikowały zniecierpliwienie i chęć powrotu do normalności, w której ramach miały wypracowane standardowe i rutynowe sposoby działania.

(...) ja już jestem zmęczona tą całą pandemią, tym wirusem, tym, że nie wiem, czy moje dziecko wróci do przedszkola... Ja się pytam: Kiedy to wszystko się skończy? Chcę normalności (70).

Instamatki zwracały również uwagę na ograniczenia realizacji ról macierzyńskich, wynikające z presji, którą narzuca na nie otoczenie. Wskazywały na różnorodność podejść do wypełniania rodzicielskich obowiązków i chęć popularyzowania postulatów akceptacji tych podejść. Jest to rezultat afirmowania różnorodności kobiet w przestrzeni wirtualnej Instagrama. Instamamy powstrzymują się od oceniania innych kobiet czy nadinterpretowania ich zachowań. Wskazują jedynie na różnice indywidualnych strategii działania matek i normalizują je.

\begin{abstract}
Jedne z nas wspaniale odnajdą się w macierzyństwie i na dobre porzucą swoje zawodowe plany, inne wręcz przeciwnie - udowodnią sobie i całemu światu, że choć potomstwo i kariera nie zawsze idą ze sobą w parze, (...) nie ma dla nich rzeczy niemożliwych i zawzięcie dążą do realizacji swoich celów, nie patrząc na przeszkody, które napotykają każdego dnia; to wręcz je bardziej motywuje do działania (143).
\end{abstract}

Matki aktywne na Instagramie szukają konstruktywnych rozwiązań problemów, z którymi się mierzą. Instagram jest dla nich pewnego rodzaju współczesnym pamiętnikiem, który pozwala porządkować przemyślenia i refleksje. Ich wyrazem są wpisy mające charakter porad, myśli motywacyjnych, słów wsparcia dla innych matek, znajdujących się w podobnych sytuacjach. Rady dawane innym użytkowniczkom Instagrama są nacechowane pozytywnie; nie ma w nich przejawów mowy nienawiści. Kobiety doradzają sobie wygenerowanie czasu na odpoczynek i realizowanie pasji, cierpliwość i akceptację samych siebie.

Właśnie skończyłam prowadzić zajęcia on-line, a mój mąż za chwilę wyjdzie z pokoju Młodego i powie: „śpi spokojnie”. Wspólnie złożymy sprzęt do transmisji, odstawimy meble na miejsce i będziemy mogli skorzystać z wieczornej ciszy. Po całym dniu pracy należy się (261).

Balansowanie pomiędzy dopołudniowymi eksperymentami a popołudniowymi zabawami z maluszkiem. Syn rozdaje karty snu. Potrzebna jest kawa, cierpliwość, zrozumienie potrzeb każdego z domowników, łagodzenie napięć i dużo uśmiechu (287). 
Matki zwracają w postach uwagę na swoją wielozadaniowość i ponadprzeciętne umiejętności organizowania czasu całej rodziny, choć polecają sobie również korzystanie z pomocy w opiece nad dziećmi i nad gospodarstwem domowym, o ile takie wsparcie mogą zaoferować inni członkowie rodziny.

Ja bym chciała mieć jeden wyznaczony czas na ogarnianie kalendarza, rachunków, planowanie, social media firmowe itp., w którym nikt mi nie przeszkadza... Ale nie ma tak dobrze... Wszystko w międzyczasie, żonglując dziećmi, logistyką i pozostałymi obowiązkami (78).

Co ważne, aktywne na Instagramie matki zdają sobie sprawę ze swoich mocnych stron i informują o nich obserwatorów swoich profili. Ich narracje nie mają charakteru usprawiedliwień niekompetencji, tylko rzetelnych bilansów sytuacji, w jakich musiały się odnaleźć w okresie pandemii.

\section{Podsumowanie}

Gęsty opis codzienności instamatek w okresie pandemii pozwolił na wyodrębnienie istotnych obszarów nowej codzienności w narracjach kobiet, do których zaliczyć można: zmagania z nowymi wyzwaniami edukacji dzieci i opieki nad dziećmi w domu bez wsparcia instytucji opiekuńczo-wychowawczych, nowe emocje i doświadczenia kobiet, które redefiniują ich podejście do macierzyństwa, nowy podział obowiązków w rodzinach i konflikty, które powstają na tym tle.

Matki podkreślały w swoich postach, że nowa codzienność stanowi dla nich wyzwanie oraz że w ich rodzinach przestały funkcjonować wypracowane i rutynowe rozwiązania codzienności. Kobiety przejęły znaczną część obowiązków związanych z edukacją dzieci i opieką nad nimi, redukując czas, który mogą poświęcać pracy zawodowej bądź pracując w o wiele trudniejszych niż dotychczas warunkach (np. w nocy lub w obecności dzieci). Co ciekawe, pomimo deklaracji zmęczenia i przeciążenia obowiązkami autorki postów podkreślały wielokrotnie ponadprzeciętne kompetencje współczesnych matek związane z umiejętnym zarządzaniem sobą w czasie i wielozadaniowością.

W odpowiedzi na postawione w pracy pytania badawcze autorki dostrzegły, że nieco częściej o trudach codzienności komunikują matki, które miały możliwość pracy zdalnej niż te, które z racji wykonywanego zawodu nie mogły pracować „z domu”.

Pandemia w negatywny sposób oddziałuje na kondycję psychofizyczną matek, a nowa codzienność zawodowa przysparza im problemów i powoduje wzmożony stres, wynikający z braku możliwości realizacji zadań zawodowych na dotychczasowym poziomie. Jednak narracje kobiet nie stanowią usprawiedliwień, a ich komunikaty nie są narzekaniem na codzienność, w której funkcjonują. Instamamy konstruktywnie oceniają rzeczywistość, komunikują o swoich nowych potrzebach, oczekiwaniach i nowych sposobach rozwiązywania problemów rodzicielskich czy zawodowych.

Warto jednak podkreślić, że choć matki pracujące w badanym okresie pandemii mierzyły się z wieloma trudnościami związanymi zarówno z pracą zawodową, jak i łączeniem 


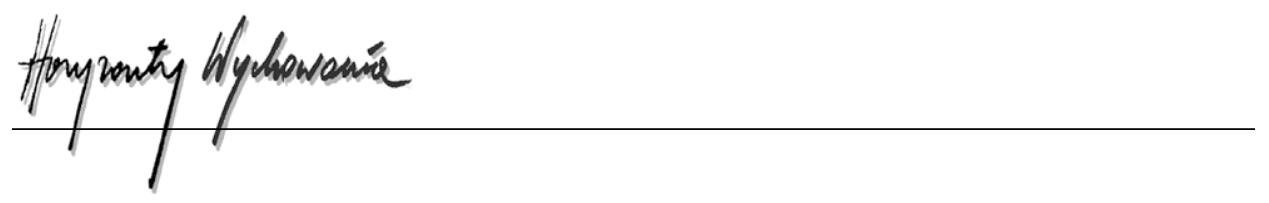

ról mamy, pracownicy, szefowej czy żony, większość badanych kobiet w swoich publikacjach wskazuje na możliwości, jakie przyniósł im ten niezwyczajny czas pandemii.

\section{BIBLIOGRAFIA}

Bednarska, M. (2020). Zamiast wprowadzenia. Wychowanie dziecka w otoczeniu mediów. W: N. Bednarska (red.), Dziecko - media - rozwój. O konsekwencjach obecności mediów w życiu dziecka (s. 9-16). Wydawnictwo Akademii Pedagogiki Specjalnej.

Belanche, D., Flavián, M. i Ibáñez-Sánchez, S. (2020). Followers' reactions to influencers' Instagram posts. Spanish Journal of Marketing-ESIC, 24(1), 37-53.

Boerman, S.C. (2020). The effects of the standardized Instagram disclosure for micro-and meso-influencers. Computers in Human Behavior, 103, 199-207.

Buksa, Ł. i Luber, M. (2020). Matka XXI wieku. Funkcjonowanie instamatki w cyfrowym świecie. W: J. Kawa i M. Stradomska (red.), Kwestie i problemy społeczne współczesnego świata (t. 1, s. 53-66). Wydawnictwo Naukowe Archaegraph.

CBOS. (2019). Oszacowanie rozpowszechnienia oraz identyfikacja czynników ryzyka i czynników chroniących hazardu i innych uzależnień behawioralnych - edycja 2018/19. Raport z badań. Krajowe Biuro ds. Przeciwdziałania Narkomanii, Ministerstwo Zdrowia, CBOS. https://www.

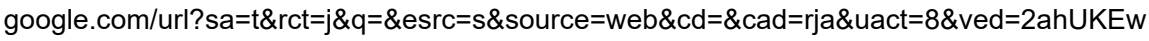
jwgqv6487vAhWD2uAKHQPxDTcQFjAAegQIAxAD\&url=https\%3A\%2F\%2Fwww.kbpn.gov. pl\%2Fportal\%3Fid\%3D15\%26res_id\%3D9249205\&usg=AOvVaw1KUwbAoY6pkjOl60_whNnu

Deloitte. (2021). Wpływ pandemii na perspektywy rozwoju zawodowego kobiet w biznesie. Jak pracodawcy mogą wspierać rozwój kobiecych talentów. Raport z badania. https://www2.deloitte. $\mathrm{com} / \mathrm{pl} / \mathrm{pl} /$ pages/kobiety-w-biznesie/articles/raport-wplyw-pandemii-na-perspektywy-rozwoju-zawodowego-kobiet-w-biznesie.html

Eurofound. (2020). Living, working and COVID-19. Eurofound. https://www.eurofound.europa.eu/ publications/report/2020/living-working-and-covid-19

Geertz, C. (2003). Opis gęsty - w stronę interpretatywnej teorii kultury. W: M. Kempny i E. Nowicka (red.), Badanie kultury: element teorii antropologicznej (s. 35-58). Wydawnictwo Naukowe PWN.

Grotowska, S. (2019). Obraz macierzyństwa w polskiej blogosferze parentingowej. Horyzonty Wychowania, 18(45), 23-33.

GUS. 2021. Monitoring Rynku Pracy. Kwartalna informacja o rynku pracy w czwartym kwartale 2020 r. https://stat.gov.pl/obszary-tematyczne/rynek-pracy/pracujacy-bezrobotni-bierni-zawodowo-wg-bael/monitoring-rynku-pracy-kwartalna-informacja-o-rynku-pracy-w-czwartym-kwartale-2020-r-, 12,45.html

IAB Polska. (b.d.). Przewodnik po social media w Polsce. Pobrano 22 lutego 2021 r. z: https:// www.iab.org.pl/wp-content/uploads/2020/01/IAB-Przewodnik-po-Social-Media-w-Polsce-2019-2020-1.pdf

Kemp, S. (2020). Digital 2020: October Global STATSHOT. https://datareportal.com/reports/ digital-2020-october-global-statshot

Kowalska, M. (2016). Polskie kobiety jako użytkowniczki mediów społecznościowych. Marketing i Rynek, 3(16), 367-378.

Krasnova, A. i Mizera-Pęczek, P. (w druku). \#mamawracadopracy-Instagram jako przestrzeń wymiany informacji o dylematach matek związanych z powrotem do pracy po urlopach macierzyńskich

Łosiewicz, M. (2020), Blogi parentingowe jako platforma (auto)prezentacji współczesnej polskiej rodziny. Horyzonty Wychowania, 19(49), 127-139. 
Młyński, J. (2020). Rodzina w sytuacji pandemii koronawirusa COVID-19 jako wyzwanie dla polityki lokalnej. W: N. Pikuła, M. Grewiński, E. Zdebska i W. Glac (red.), Wyzwania dla polityki społecznej w kontekście pandemii koronawirusa (s. 69-88). Wydawnictwo Scriptum.

Moujaes, M. i Verrier, D. (2020). Instagram use, instamums, and anxiety in mothers of young children. Journal of Media Psychology: Theories, Methods, and Applications. Advance online publication. https://doi.org/10.1027/1864-1105/a000282

Pluta, M. (2020). \#breastcancer - wspierająca rola Instagrama dla kobiet z rakiem piersi. W: P. Siuda i M. Pluta (red.), Internet, zdrowie i choroba. Powiązania społeczne, kulturowe i edukacyjne („Kultura medialna i komunikacja społeczna”, t. 2, s. 20-44). Wydawnictwo Uniwersytetu Kazimierza Wielkiego.

Raport (b.d.). Raport Mama-Warszawianka. Mama na rynku pracy. Wygrajmy z COVID-em. Fundacja Sukcesu Pisanego Szminką. Pobrano 27 lutego 2021 r. z: https://www.um.warszawa.pl/ sites/all/files/download_file.php?file=/sites/default/files/attach/aktualnosci/raport_mama_warszawianka_listopad_2020.pdf

Urbaś, J. (2021). Instamatka ekspertka - rola Instagrama w upowszechnianiu wiedzy o tematyce dziecięcej. Studia Socialia Cracoviensia, 11(1), 75-89.

Uzależnienia behawioralne. (b.d.). „Młode matki najintensywniej korzystają z Instagrama”. Czy to one są najbardziej zagrożone uzależnieniem? Pobrano 15 lutego 2021 r. z: https://www.uzaleznieniabehawioralne.pl/raporty-z-badan/siecioholizm-raporty-z-badan/mlode-matki-najintensywniej-korzystaja-z-instagrama-czy-to-one-sa-najbardziej-zagrozone-uzaleznieniem-od-tego-medium/

Wicińska, K. (2017). Media społecznościowe jako narzędzie rozwijające działania marketingowe przedsiębiorstw. Rynek - Społeczeństwo - Kultura, 3(24), 115-121.

Zub, M. (red.). (2020). Analiza społeczno-gospodarcza wraz z diagnozą obszarów interwencji EFS. Raport końcowy. Ministerstwo Funduszy i Polityki Regionalnej. https://www.power.gov.pl/ media/98143/Analiza_spolgosp.pdf

\section{Copyright and License}

This article is published under the terms of the Creative Commons Attribution - NoDerivs (CC BY- ND 4.0) License http://creativecommons.org/licenses/by-nd/4.0/ 